\title{
Las escalas de actitud como género discursivo en la esfera investigativa
}

\section{(Attitude scales as a discursive genre in the research field)}

\author{
*Tomás Fontaines-Ruiz \\ Universidad Técnica de Machala, Machala - Ecuador \\ *Email de correspondencia: tfontaines@utmachala.edu.ec
}

\section{RESUMEN}

Este trabajo de investigación nace del interés en someter a comprobación el comportamiento lingüístico de las escalas de actitud, comúnmente utilizadas con dificultad por los investigadores en ciencias sociales, para determinar su complexión como una tipología textual. El estudio se llevó a cabo mediante un análisis contrastativo de las escalas actitudinales y categorías teóricas. Las escalas de actitud se caracterizaron y se acompañaron de un anclaje teórico para proveer una mejor comprensión del trabajo. A modo de conclusión, se determinó que las escalas de actitud pueden ser identificadas como un género discursivo que tiene como propósito principal, la valoración de la presencia de cualidades en principios humanos a través de un modo de organización discursiva descriptivo que favorece la relación entre un escritor experto y un lector semilego. De igual forma, se precisó que el contexto de circulación de las escalas de actitud es diverso y la modalidad semiótica predominante de estas es la multimodal.

Palabras clave: escalas de actitud; genero discursivo; tipología textual; escritor experto; lector semilego, multimodalidad.

\begin{abstract}
This research work arises from the interest in subjecting the linguistic performance of attitude scales, commonly used with difficulty by social science researchers, to determine their nature as a textual typology. The study was conducted by a contrastive analysis of attitudinal scales and theoretical categories. Attitude scales were characterized and accompanied by a theoretical framework to provide a better understanding of the work. As a conclusion, it was determined that attitude scales can
\end{abstract}


be identified as a discursive genre whose main purpose is the assessment of the presence of qualities in human principles through a descriptive discourse organization that promotes the relationship between an expert writer and a semi-expert reader. Likewise, it was stated that the context of utilization of attitude scales is diverse, and their predominant semiotics mode is the multimodality.

Keywords: Attitude scales, discursive genre, textual typologies, expert writer, novice reader, multimodality. 


\section{A MODO DE INTRODUCCIÓN}

Este estudio asume que en la acción de investigar se producen tramas textuales de diversa naturaleza y secuencia, las cuales condicionan la posibilidad de hacer inteligible el objeto de estudio, la recolección de información sobre su comportamiento y la traducción del dato en conocimiento probable.

Lógicamente, lo tramado del hecho investigador se justifica en el uso de una variedad de tipologías o géneros textuales para representar al objeto y hacerlo comprensible, en un primer momento por el investigador, quién configura las características estructurales y dinámicas del objeto bajo estudio y luego, en un momento posterior, por la comunidad usuaria del saber generado (receptor). Este proceso va a tener un carácter recursivo y será garante de la continuidad de líneas de desarrollo temático, también conocidas como líneas de investigación.

Lo anterior, deja entendido que tramar discursos supone vincular textos de diversos tipos (expositivos, narrativos, argumentativos) cuya vinculación está sujeta a la necesidad del investigador, las características de lo investigado y el nivel de profundidad del conocimiento que la comunidad científica tiene sobre el carácter ontológico del objeto. Pero en esta vinculación del investigador con los textos, pueden darse dos situaciones que valdría la pena exponer. En primer término, el uso consciente de diversos tipos textuales, esto soportado en lo que Beugrande y Dressler (1997, p. 17) explican sobre la imposibilidad de entender textos en solitario sino en su intertextualidad; aunado al rescate de la idea de Adam, respecto a que no existen textos puros; existen textos donde se integran secuencias prototípicas de naturaleza diversa, desde donde se forma una especie de intertipologicidad. En segundo término, aparece la idea de hacer uso de modo recurrente de tipos textuales que hasta el momento han pasado inadvertido como un género pero que se comportan como tal.

A la luz de esta segunda consideración se instala esta investigación que pretende someter a escrutinio el comportamiento lingüístico de los cuestionarios, específicamente las escalas de actitud, a través de un análisis contrastativo con categorías teóricas que serán desarrolladas más adelante, a fin de determinar su complexión como una tipología textual. El estudio pretende develar el sistema lingüístico que subyace a este tipo de escalas, comúnmente usadas por los investigadores en ciencias sociales, con un significativo porcentaje de dificultad, por el desconocimiento, entre otras áreas, de sus características textuales, las cuales proveen caminos para comprender como se estructura e interactúa con el contexto las escalas, cómo se entregan al investigador en nombre de la intertextualidad y desde allí, pasan a ser el medio para encontrar al investigador con el dato, extraerlo y estructurarlo para su posterior análisis.

Se debe aclarar que en el terreno de lo académico se registran estudios que buscan entender el carácter textual que tienen diversos elementos de la dinámica de investigación, me estoy refiriendo específicamente a los modos de citas (Beke, 2008), ponencias y artículos (Bolívar, 2004; Beke, 2005), informes de arbitraje y evaluación de publicaciones (Bolívar, 2008). No obstante, adentrarnos en entender el funcionamiento textual e intertextual de las técnicas e instrumentos de recolección de datos y su posterior sistema de análisis, no ha sido estudiado en profundidad, o al menos, en esta investigación, no se han encontrado evidencias de ello. Esta realidad probablemente esté vinculada a las barreras disciplinares que se perciben en el desarrollo de la investigación social, que desconocen el comportamiento textual de sus productos y que todo texto se tiñe del contexto (en este caso socio-disciplinar) para poder ser significado.

Una muestra de este comportamiento se observa al estudiar la estructura del momento metodológico en una investigación social de base empírico inductiva, donde se debe cumplir los lineamientos de la teoría de muestreo, de diseños de investigación, los psicotécnicos para la estimación de validez y confiabilidad, los procedimientos establecidos para la construcción de escalas de investigación y por supuesto, las leyes estadísticas para el análisis de los resultados. 
En este sentido, pareciera que cada segmento de este aparato de la investigación funciona sólo y el carácter interdependiente que subyace a su discurso se diluye en las exigencias que desde cada terreno disciplinar se realiza, en aras de dar garantía de objetividad y rigurosidad como valores primigenios en este tipo de investigación (Camacho y Fontaines, 2004).

Esta evidencia fortalece aún más la crítica establecida en relación con el desconocimiento del funcionamiento textual de las escalas y de su interacción cotextual y contextual que le permite ser un medio entre el investigador y la muestra y así poder lograr capturar la información necesaria para responder los objetivos del estudio.

Buscando garantizar la comprensión de la lógica de esta investigación, inicialmente, expondré una caracterización del objeto de esta investigación (escalas de actitud), luego se desarrollará el anclaje teórico del estudio, el momento metodológico de la investigación (descripción del corpus de análisis y especificación de la secuencia operativa). Finalmente se mostrará el análisis establecido y las conclusiones derivadas de la investigación.

\section{EL CORPUS-OBJETO DEL ESTUDIO: LAS ES- CALAS DE ACTITUD}

Las escalas de actitud se encuentran clasificadas como instrumentos de recolección de datos. En sentido general son herramientas $u$ objetos materiales que resultan de un proceso sistemático (construcción, administración, y procesamiento de datos), mediante el cual se confronta a los sujetos de la muestra en estudio, con un conjunto de reactivos o ítems a fin de obtener representaciones del comportamiento de la variable en él o los sujetos analizados. Su condición de producto de un proceso sistemático, obedece a que, en su elaboración, el instrumento de medición pasa por una serie de etapas que van desde la selección del tipo de instrumento o escala a utilizar, su diseño-estudio técnico, hasta la edición final para ser aplicado a la muestra. En consecuencia, quien lo construye debe tener o desarrollar las habilidades necesarias para precisar los fundamentos teóricos que sustentan los atributos de la variable en estudio; asimismo, implementar los criterios para la redacción de los ítems y aplicar los procedimientos estadísticos que apoyarán la edición de un instrumento confiable y válido.

Buscando establecer una caracterización más específica, las escalas de actitud (formato Lickert, Thurstone, Osgood) nacen a finales de los años treinta, tomando como antecedente los planteamientos de Thurstone. Se pueden definir como escalas aditivas que consisten en proponerle al sujeto una serie de ítems o reactivos con la finalidad de estimar su reacción o identificación frente a ellos (para revisar a fondo el tema considerar revisar: Kerlinger, 1988; Hernández, Fernández y Baptista, 2003)

Entre las características más resaltantes se encuentran las siguientes:

a. Es de naturaleza ordinal.

b. La proporción de ítems que constituye su extensión varía de acuerdo a la magnitud de la variable a medir.

c. Desde el punto de vista psicométrico se considera centrada en el sujeto, de allí que destaque las diferencias interindividuales.

d. Las opciones o alternativas de respuesta varían entre 3, 4, 5 o más, las cuales se denotan cualitativamente de distintas formas.

e. Las alternativas de respuesta se corresponden con valores numéricos, que permitirán cuantificar el atributo objeto de medición.

Es importante señalar, que la decisión sobre el número de alternativas de respuestas y la asignación de los puntajes está sujeta al criterio del investigador. Sin embargo, es recomendable ajustar las opciones a números pares. De esta manera, se induce al sujeto a que exprese una preferencia en función al constructo indagado.

\section{ANCLAJE TEÓRICO DEL ESTUDIO}

La investigación de los textos ha crecido gradualmente en la comunidad de investigadores, al punto de registrarse publicaciones dedicadas a

\section{Cumbres}


reconstruir el proceso diacrónico de las escuelas que han abordado el caso (Simón, 2006), comparaciones en cuanto a la concepción de lo textual desde posiciones lingüísticas diversas (Ciapuscio, 2005), hasta encontrarse casos donde, a partir de posiciones clásicas, y de intentar comprender sus aciertos y desaciertos se atreven a mostrar su propia perspectiva para entender lo textual (Charaudeau, 2004).

Ciertamente, estas publicaciones son un síntoma de los diversos caminos para comprender lo textual y su mecanismo de interacción y en nombre de esa diversidad, en esta investigación, asumiremos el anclaje teórico en dos perspectivas: la primera dirigida a esclarecer los anclajes teóricos de apoyo, definidos como los elementos que explican el funcionamiento de lo textual y su vinculación interactiva con el entorno, para lo cual, partiré de los aportes de la lingüística textual (Ciapuscio, 1994, 2003). La segunda perspectiva teórica que se considera en este estudio, la denominaré anclaje teórico de servicio, a la luz de la cual se pone la teoría al servicio de lo procedimental. Es decir, se utiliza como marco referencial que fundamenta el diseño de la investigación y por tanto la relación gnoseológica que se teje en todo proceso de investigación. En este sentido, consideraré los aportes de la teoría lingüística asociada a lo multinivel desarrollada por Parodi (2008) y Parodi y Gramajo (2003). Ambos anclajes se desarrollan a continuación:

\subsection{Anclaje teórico de apoyo}

\section{a. Géneros textuales y funcionamiento}

El estudio de los géneros textuales ha interesado de modo creciente a los investigadores, entre otras razones, por el reconocimiento de que determinados textos tienen pautas establecidas de estructuración y funcionamiento, y como consecuencia de ello, formas típicas de expresión lingüística, que homogenizan la dinámica comunicacional. Por tanto, es admisible pensar que la comprensión de lo textual como género, permite entender modos de comunicación, propósitos comunicativos, reglas comunicacionales. Esto explicaría su abordaje desde lo etnográfico, sociológico, psicológico, educativo, y lógicamente, lingüístico.

En este sentido, la literatura especializada exhibe multiplicidad de concepciones y caracterizaciones que pudieran tener su origen en dos fuentes complementarias que vale la pena comentar: a) las características estructurales y dinámica que asume el texto dentro de un determinado género y b) las especificidades discursivas de las comunidades de investigadores quienes legitiman la estructura diacrónica-sincrónica del género.

Por esta razón, considero necesario exponer cómo se expresan las multiplicidades conceptuales con sus respectivas discrepancias, e introducir posibles ángulos de convergencia entre las aparentes divisiones, que en el plano teórico se acentúan, pero que en el terreno discursivo se muestran tramadas.

En una perspectiva diacrónica, el abordaje de los géneros se pudiese situar en Grecia, en una época donde lo discursivo, filosófico y peripatético marcan el foco cultural del momento (Fontaines, Camacho y Finol, 2010). Es Aristóteles quien en su retórica apertura una clasificación del género en tres tipos: género forense o jurídico, género deliberativo o político, género demostrativo o epidíctico. No obstante, el fin de la retórica es persuadir. En esta oportunidad, no contamos con elementos de base para entender la noción de género textual como la conocemos hoy. Se evidencia una clasificación sobre sus tipos, pero no como un objeto de estudio, sino como un adjetivo que tipifica una acción comunicativa. Con esto quiero expresar que la intención del estagirita no es ahondar en el género; le interesa es persuadir mediante la acción comunicativa y en esa dirección estructura su obra.

A juicio de Calvi (2010) es Bajtin quien apertura el estudio formal del género textual abordándolo como objeto de estudio. En su estética de la creación verbal, Bajtin (1978) deja establecida la presencia de géneros primarios de la comunicación oral y los secundarios o creados (políticos, académicos, de investigación, etc.), desde donde se empiezan a consolidar bases para argumentaciones posteriores.

Con Swales (1990, p. 58) se evidencia la idea 
del género como una clase de eventos comunicativos con propósito comunicacional específico; de allí la base de su racionalidad y las estructuras esquemáticas que este adopta en el discurso, a partir de la cual se explican las restricciones de contenido y estilo. Como lo indica Paltridge (1994), la influencia del precitado autor va a estar circunscrita, entre otras razones, a la exposición de una estructura para abordar los géneros. Esta postula el reconocimiento de: el propósito comunicativo, la estructura, estilo, contenido, audiencia de género.

Conviene dejar establecido que estas caracterizaciones tienen un comportamiento invariable. Todo género las presenta sin distinción de su tipificación. Es más, a partir de estas características van a tener sentido las aproximaciones y caracterizaciones de las tramas textuales. En palabras de Bazerman (1999), los cambios que vendría a experimentar la noción de género marcarían su necesidad de abordaje. Gracias a su comprensión se pueden acceder a los códigos comunicacionales de determinadas comunidades científicas, lo que se traduce en aprendizaje de arquetipos teóricos, rutinas metodológicas, modos de expresión del conocimiento verdadero, sistemas de argumentación de la verdad atendiendo el criterio de demarcación epistemológico asumido.

En estas primeras ideas aparece una noción que va a marcar el inicio del debate al que me refería en la introducción de este apartado. Estoy aludiendo a las comunidades de investigadores, las cuales, a pesar de ser un sistema abierto, en ocasiones tienden a mostrar un comportamiento cerrado al aferrarse a sus nociones teórico-epistemológicas y metodológicas. Calsamiglia y Tusón (1999:253) exponen una muestra de ello cuando manifiestan que en el proceso de clasificación de los géneros textuales diversos han sido los criterios empleados, estando entre los más connotados: criterios funcionales, enunciativos, bases cognitivo-textuales, esquemas de organización del texto, entre otros. Ciapuscio (2005) recopila muestra de estos enfrentamientos, dando paso a las comparaciones entre la noción de género en la lingüística sistémico funcional y la textual.

Desde lo sistémico funcional, el género se orienta a desentrañar la idea de lenguaje como regla, pero en interacción. Esta visión pone en evidencia los corolarios de Halliday (2004) sobre la interconexión lenguaje-sociedad, para poder significarse, dejando claro que en la interacción cobra sentido la comunicación cuya variabilidad le ofrece el calificativo de compleja y entrópica. Estos elementos son reforzados en las ideas de Fairclough (1995) cuando fragmenta la barrera de lo textual-escrito y potencia la noción de texto como artefacto cultural.

Esta visión no significa que se rompe con los valores empíricos del género textual como un objeto de estudio científico, por el contrario, deja constancia del modo en que las comunidades de investigadores tienden a reconocer manifestaciones textuales y las introyectan a fin de poder sustantivarse y desarrollarse en cuanto a potencial discursivo, acrecentando su territorio de acción. Pero además de ello, pensar el género textual desde esta óptica supone reconocer que las comunidades crean y socializan sus propias normas comunicacionales para demarcar aquello que es producto de su desarrollo.

En la lingüística textual se observa un debate marcado en la consideración de los géneros debido a la diversificación interna que ha experimentado esta tendencia (Ciapuscio, Kagel y Otañi, 2005) atendiendo a los énfasis en el modo de concebir el texto, su dinámica e interacción. Ciapuscio (2005) partiendo de los aportes de Brinker y Heinemann, se hace portavoz de esta tendencia lingüística señalando los géneros como una especie de estructuras de clasificación derivadas del carácter estructural del texto y de su uso en la cotidianidad, expresiones semejantes a las de Loureada (2003) cuando rescata el carácter comunicativo-pragmático y el estructural interno del texto como criterios empleados para tipologizarlos. La lingüística textual rescata el carácter accional del texto y su uso en esquemas comunicacionales específicos. Además, presta especial atención al uso de los recursos lingüísticos para llevar a cabo el proceso comunicacional, dando origen al estudio de la recurrencia de eventos y por tanto la gradual configuración de tipologías.

A pesar de estas distinciones, la finalidad de

\section{Cumbres}


estudiar los géneros textuales es dar cuenta de las realidades del mundo de los textos y por tanto Bhatia (2002) revela un conjunto de elementos que suscriben la posibilidad de identificar una especie de condiciones invariantes en la noción de género (algo semejante a los aportes de Swales (1990). Para la autora, reconocer la presencia de distintas marcas lingüísticas y la diversidad geohistórica donde estas tienen lugar ha animado el estudio de los géneros, con la finalidad de cuestionar, aplicar resultados, o saber qué hace la gente con el lenguaje, cómo se construyen los arquetipos teóricos. A tal efecto, en esa pretensión de entender cómo funcionan los géneros textuales, devela una serie de marcas invariables que vendrían a reconciliar las diferencias que al respecto se tengan. Estas son las siguientes:

a. Son dinámicos y se encuentran en constante desarrollo: por el hecho de no existir géneros puros, se asume que se muestran vinculados al contexto y a la realidad de las comunidades donde se generan, de allí que los cambios estructurales y funcionales de las comunidades científico-discursivas, traerá como consecuencia variaciones en la noción de géneros, permitiendo hasta la conformación de subgéneros como producto de las interacciones texto-contexto-texto.

b. Son obligados a responder a fines individuales por encima de su capacidad funcional.

c. Teóricamente se muestran en estado puro, pero en la práctica -debido a su interdependencia funcional- se perciben en relación endogámica y exogámica

d. Las confrontaciones en el modo de entender y concebir un método están condicionadas por los diversos nombres que se le asocian.

e. Son independientes de los cambios disciplinarios, a pesar de que las variaciones disciplinares den origen a nuevos géneros o sub-géneros.

f. Pueden ser abordados desde diversas perspectivas metodológicas.

En esta misma línea integracionista, se pude agregar algunos aspectos que serían complementarios a los de Bathia (2002), y en este sentido, Ezpeleta (2005) nos permite asumir que los géneros:

a. Se definen a partir de propiedades exter- nas que condicionan las características internas de los textos.

b. Invocan y conforman a los interlocutores que participan en los procesos comunicativos.

c. Influye en el modo de organización del material informativo.

d. Permite la socialización emisor-receptor-comunidad discursiva mediante la adquisición de su competencia.

e. Inciden en la conformación de estructuras paradigmáticas por su carácter mediador entre el texto y el contexto.

f. Activan el proceso de lectura mediante la activación de expectativas en los lectores respecto a su contenido.

Partiendo de los referentes anteriores se puede concluir que la noción de género textual la vamos a asumir como un sistema de clasificación dinámico y flexible, una interfaz ente texto y contexto, que afecta de modo dialéctico la percepción de quien hace el texto y quien los usa, por requerir de competencias discursivas operacionalizadas mediante roles sociolectales (Herrero Cecilia, 2006), cuya finalidad es establecer convenciones para comprender la estructura y funcionamiento de los mismos y de esta manera, garantizar el éxito del proceso comunicacional y aprendizaje de los contenidos que en ellos se encuentran plasmados. A la luz de lo comentado quisiera exaltar el carácter de adaptabilidad estructural del género a las imposiciones contextuales y cómo Estas son transformadas en sistemas de géneros (Orlikowski \& Yates, 1998) atendiendo a las necesidades comunicacionales de los grupos humanos que gradualmente se van comportando como comunidades discursivas, con improntas particulares.

Es esta característica la que le otorga mayor dinamismo al género. Incluso, podemos reconocerle complicidad en la consolidación del aprendizaje de determinadas áreas. Especulando un tanto más, el concepto de género permitiría establecer que mientras más conocemos cómo las comunidades se apropian o van configurando, mediante sistemas de hibridación, determinados géneros textuales, existe mayor garantía de asimilar, acomodar y por ende organizar los 
constructos teóricos que sirven de soporte a la conformación de determinados perfiles profesiográficos con sus respectivas orientaciones socio-discursivas.

3.2. Anclaje teórico de servicio.

a. Las tipologías textuales desde una óptica multinivel: Estructura y dinámica.

Como se ha expuesto, existe diversidad de criterios al momento de emplazar la configuración y funcionamiento de los géneros textuales. Como parte de este debate, Parodí (2008) plantea una crítica respecto a las orientaciones encuadradas en el comportamiento morfosintáctico del texto y a aquellas que se inclinan por favorecer el carácter pragmático del mismo. Al respecto, esgrime la necesidad de realizar un abordaje integral del género, ilustrando para ello la propuesta cognitiva, cuyos rasgos constitutivos pasaré a comentar como elemento de base para entender la propuesta multinivel que metodologiza el autor y que será la empleada en el análisis de la presente investigación.

La perspectiva socio-constructivista de los géneros textuales integra elementos propios de la psicología soviética y los pone a nivel del funcionamiento de lo lingüústico entendiéndolo como una interfaz de conexión entre el contexto social y el contexto privado del individuo. De esta manera, se reconoce el lenguaje como medio para el desarrollo del pensamiento y a la interacción social como el espacio donde este tiene cabida.

Con base en lo comentado, los géneros se van configurando y delimitando en la medida que se produce la interacción humana y aparecen comportamientos discursivo-lingüísticos, hasta el punto de crearse una especie de impronta característica de un tipo de manifestación textual. En este sentido, realzo el supuesto de que los géneros no se decretan, estos gravitan en la acción comunicativa y son identificados mediante un escrutinio categórico de cara a su carácter estructural, funcional y contextual. Este escrutinio responde a una observación empírico-inductiva y atiende específicamente la recurrencia de aparición de esos rasgos lingüísticos que más tarde condicionarán la definición del género o tipo textual.

Para Parodi (2008), los géneros deben ser entendidos de modo integral, y por tanto postula seis categorías para ello: soporte, condiciones de circulación, propósitos comunicativos, participantes, rasgos léxico-gramaticales, modos de organización discursiva. No obstante, debo aclarar que el autor plantea una posibilidad abierta de integrar categorías adicionales según la necesidad de la realidad textual indagada.

Bajo esta óptica de análisis Parodi y Gramajo (2003) adelantan una investigación sobre tipos textuales, produciendo una metodología caracterizada por lo multinivel, tomando como referencia los escritos derivados de la lingüística textual y la lingüística de corpus. Tal como se muestra en la Figura 1. Los autores tejen una propuesta centrada en el carácter lingüístico, contextual e interactivo del texto. Como puede notarse, los

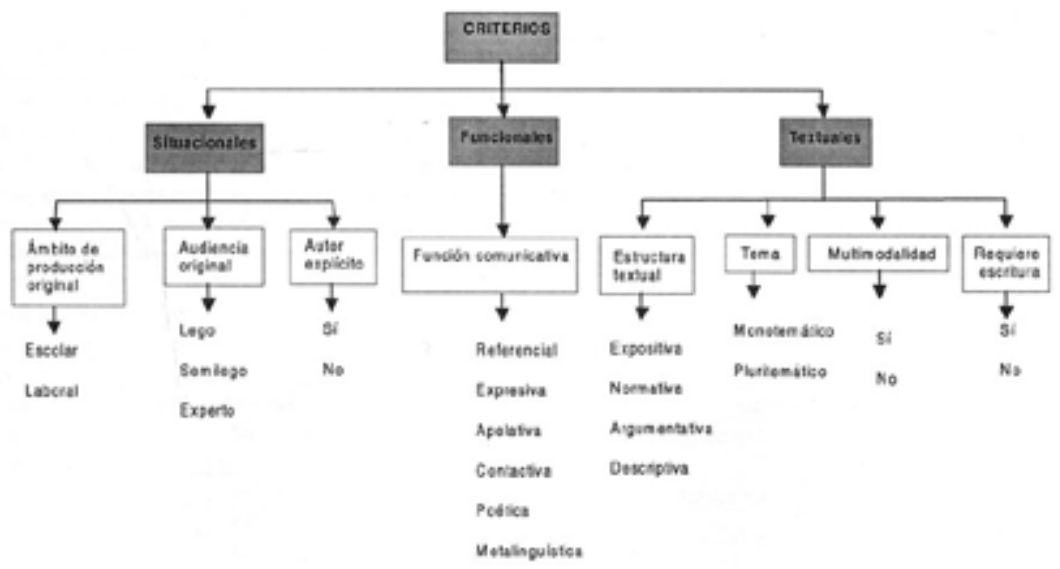

Figura 1. Criterios y rasgos de clasificación textual. Fuente: Parodi \& Gramajo (2003)

criterios nacen de tres ejes principales: situacionales, funcionales y textuales.

El primero de ellos recata el carácter contextual que vendría a significar y en ocasiones a re-significar semánticamente el texto y al mismo tiempo, a condicionar la interacción entre el texto y sus usuarios. El criterio funcional se enfoca en el propósito comunicativo tomando como refe-

\section{Cumbres}


rente las conocidas funciones comunicativas de Jakobson. Por último, el criterio textual permite dar cuenta del modo de organización del texto. Desde esta perspectiva teórico-metodológica, los textos objeto de clasificación son sometidos al escrutinio de los criterios precitados, para de esta manera, poder ser conceptualizado y sistematizados desde una perspectiva conceptual y operacional.

Esta metodología para abordar los géneros textuales va a ser sometida a un conjunto de reflexiones respecto al carácter global de los textos y su carácter sistémico, dando lugar a una ampliación caracterizada por la presencia de cinco criterios los cuales se muestran en la Figura 2 y se describen a continuación (Parodi, Ibáñez y Venegas, 2009, pp. 83-88).

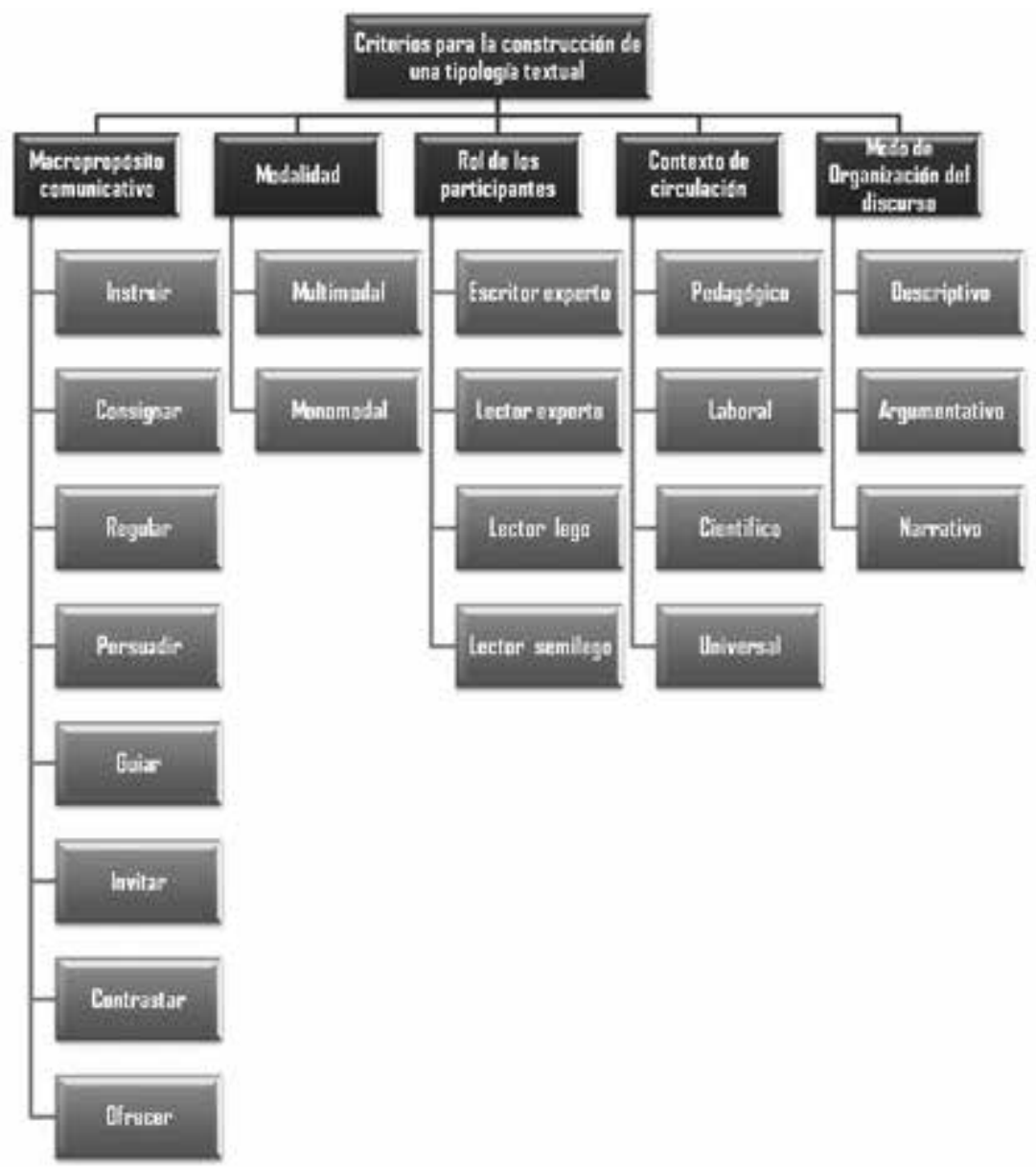

Figura 2. Criterios para la construcción de una tipología textual Fuente: Parodi et al. (2009) a. Macropropósito comunicativo: establecen la intención del texto dentro de la acción comunicativa. Al respecto es de aclarar que aparecen casos sobre géneros con propósitos comunicativos menores que interactúan entre sí y configuran un propósito mayor, siendo este el objeto de nuestro interés. Entre ellos se registran: instruir, consignar, regular, persuadir, guiar, contrastar, invitar, ofrecer.

b. Modo de organización del discurso: refiere la identificación de aquellos enunciados que condicionan la secuenciación del contenido, dándole a los textos predominios narrativos, descriptivos o argumentativos.

c. Relación entre los participantes: esta categoría se apoya en la noción de comunidades discursivas en las cuales se van consolidando competencias comunicativas desde lo más lego hasta la condición de expertos en la codificación y decodificación se los sentidos semánticos que están tramados en el texto.

d. Contexto ideal de circulación: esta categoría informa sobre los contextos de circulación donde el género tiene mayor congruencia, lo que supone establecer que existen contextos más o menos abiertos de acuerdo a los requerimientos que las comunidades discursivas le imponen. Esto explica la presencia de contextos específicos como los profesionales, laborales, y otros de orden más incluyente-universal.

e. Modalidad: en esta categoría se atienden los modos semióticos involucrados en la construcción de la red conceptual y de significados. Se expresan en dos perspectivas, a saber: a) monomodales: alude al predominio verbal (escrito u oral) y no verbal (gráficos, esquemas, tablas, esquemas, imágenes). b) multimodales: se asume esta condición cuando 
aparece un predominio dual, es decir, verbal y no verbal.

Según Parodi et al. (2009, p. 81) “El conjunto de estos criterios y variables abarca, entre otros, aspectos que dicen relación con los propósitos comunicativos, la interacción entre escritores y lectores, los contextos en que los textos circulan y los modos predominantes de organizaciones discursivas".

Dejando establecido la teoría de servicio, a continuación, se muestra el esquema metodológico que permitirá la caracterización de las escalas de actitud como género textual.

\section{METODOLOGÍA DEL ESTUDIO,}

Atendiendo el nivel de profundidad del conocimiento, el estudio se tipifica como descriptivo, teniendo como unidad de observación 14 escalas de actitud vinculadas con investigaciones referidas a las ciencias sociales. Estas unidades de observación fueron procesadas mediante los cinco criterios teóricos establecidos por Parodi et al. (2009).

\section{RESULTADOS DEL ESTUDIO.}

La muestra estudiada estuvo compuesta por 14 escalas de actitud provenientes de publicaciones arbitradas y apéndices de trabajos de investigación. Como se observa en la Tabla 1. Como criterio de selección se consideró el proceso de validez y confiabilidad al que deben ser sometidas las escalas de actitud en aras de ser empleadas como instrumentos de recolección de datos en un proceso de investigación o de práctica académica. De las escalas seleccionadas, el 57,14\% (8) pertenecen al área de la psicología educativa, el 28,5\% (4) a la psicología clínica, 7,14\% (1) a la psicología de la salud y el 7,14 (1) a la gerencia de recursos humanos. En cuanto al formato más privilegiado se obtuvo que el $71.42 \%$ (10) fueron tipo Likert, seguidos por el 21,42\% (3) del diferencial semántico y el 7,14\% (1) de orden dicotómico.

La variabilidad observada en las escalas está ligada al origen de las mismas. Este tipo de ins- trumento nace y se difunde vinculado a la práctica de la psicología diferencial y su uso fue gradualmente inervando la práctica de las ciencias sociales en general, interesadas en temáticas vinculadas con rasgos comportamentales y psicoafectivos. Para una mayor precisión al respecto, es necesario tener presente que las actitudes, como constructo teórico, son el producto de la interacción recíproca de componentes afectivos, cognitivos y conductuales, razón que justifica su empleo en el abordaje de rasgos psicológicos en diversas áreas disciplinares y temáticas.

Tabla 1. Caracterización de la muestra

\begin{tabular}{|c|c|c|c|}
\hline Código & $\begin{array}{c}\text { Area de } \\
\text { conocimiento }\end{array}$ & Area temática & $\begin{array}{c}\text { Formato de } \\
\text { escala }\end{array}$ \\
\hline 01 & $\begin{array}{l}\text { Psicología } \\
\text { educativa }\end{array}$ & $\begin{array}{l}\text { Madurez } \\
\text { vocacional }\end{array}$ & Likert \\
\hline 02 & $\begin{array}{l}\text { Psicotogia } \\
\text { educativa }\end{array}$ & $\begin{array}{l}\text { Inteligencias } \\
\text { máttiples }\end{array}$ & Likert \\
\hline 03 & $\begin{array}{l}\text { Gerencia de } \\
\text { recursos humanos }\end{array}$ & $\begin{array}{l}\text { Justicia } \\
\text { organizacional }\end{array}$ & Likert \\
\hline 04 & $\begin{array}{l}\text { Psicologia } \\
\text { educativa }\end{array}$ & $\begin{array}{l}\text { Percepcion de } \\
\text { imagen }\end{array}$ & $\begin{array}{l}\text { Difereneial } \\
\text { semantice }\end{array}$ \\
\hline 05 & $\begin{array}{l}\text { Peicologia } \\
\text { educativa }\end{array}$ & $\begin{array}{l}\text { Autovalorición } \\
\text { de la } \\
\text { matomásica }\end{array}$ & $\begin{array}{l}\text { Difercnetal } \\
\text { semantico }\end{array}$ \\
\hline 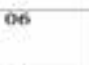 & $\begin{array}{l}\text { Ficologia } \\
\text { educativa }\end{array}$ & $\begin{array}{l}\text { Motivacion at } \\
\text { fozno }\end{array}$ & $\begin{array}{l}\text { Diferenetal } \\
\text { somantico }\end{array}$ \\
\hline 07 & $\begin{array}{l}\text { Faicotogia } \\
\text { educativa }\end{array}$ & $\begin{array}{l}\text { Inhibieison } \\
\text { escolar }\end{array}$ & Likert \\
\hline $6{ }^{2}$ & Treicologia clineica & $\begin{array}{l}\text { Preocupacion } \\
\text { infantil sobre } \\
\text { eiragia }\end{array}$ & Likert \\
\hline 09 & $\begin{array}{l}\text { Pricotogla } \\
\text { educativa }\end{array}$ & $\begin{array}{l}\text { Inhibicion } \\
\text { encolar }\end{array}$ & tikent \\
\hline 10 & Psicologia elinica & $\begin{array}{l}\text { Tdeticas de } \\
\text { contileto }\end{array}$ & Likert \\
\hline 11 & Pricologia clinica & Adiecianen & Dicatomica \\
\hline 12 & Fsicotogin elinich & $\begin{array}{l}\text { Contlietos del } \\
\text { sueno }\end{array}$ & Likert \\
\hline 13 & $\begin{array}{l}\text { Fsicologita de th } \\
\text { salud }\end{array}$ & Diabetes & Likert \\
\hline 14 & $\begin{array}{l}\text { Peicolonia } \\
\text { educativa }\end{array}$ & Autovaloración & tikent \\
\hline
\end{tabular}

Buscado acercarnos al establecimiento de las escalas de actitud como género textual, la Tabla 2. recoge el resultado de la aplicación de las categorías de Parodi et al. (2009).

Como puede notarse el macropropósito de las escalas presenta un comportamiento homogéneo en los diferentes ejemplares estudiados. En el momento en que se construyen las escalas se estructuran con la finalidad de valorar la presencia

\section{Cumbres}


o concentración del objeto de la medida en las personas que la responden. Cada escala tiene un referente temático o variable sobre la cual versa y presenta un sistema de opciones que le permiten a los respondientes u observadores representar su posición frente a los reactivos o ítems.

Siguiendo con el análisis multinivel, pasamos a identificar el modo de organización del discurso. El $\mathbf{1 0 0 \%}$ de la muestra arroja la prevalencia

Tabla 2. Comportamiento de las escalas de actitud atendiendo a las categorías multiniveles de Parodi et al. (2009)

\begin{tabular}{|c|c|c|c|c|c|}
\hline Codigo & $\begin{array}{l}\text { Macropropósito } \\
\text { comunicativo }\end{array}$ & $\begin{array}{c}\text { Modo de } \\
\text { organización } \\
\text { del discurso }\end{array}$ & $\begin{array}{l}\text { Relacióa entre } \\
\text { participantes }\end{array}$ & $\begin{array}{c}\text { Conterto } \\
\text { de } \\
\text { circulación }\end{array}$ & Modalidad \\
\hline 01 & Valorar & Descriptivo & $\begin{array}{l}\text { Lector } \\
\text { semilego }\end{array}$ & Pedagógico & Multimodal \\
\hline 02 & Valorar & Descriptivo & $\begin{array}{l}\text { Lector } \\
\text { semilego }\end{array}$ & Pedagógico & Multimodal \\
\hline 03 & Valorar & Descriptivo & $\begin{array}{l}\text { Lector } \\
\text { semilkgo }\end{array}$ & Laboral & Multimodal \\
\hline 04 & Valorar & Descriptivo & $\begin{array}{l}\text { Lector } \\
\text { semilkgo }\end{array}$ & Podagógico & Multimodal \\
\hline 05 & Valotar & Descriptivo & $\begin{array}{l}\text { Lector } \\
\text { semilego }\end{array}$ & Pedagógico & Multimodal \\
\hline 06 & Vatorar & Descriptivo & Lector experto & Pedagógico & Multimodal \\
\hline 07 & Valorar & Descriptivo & Loctor experto & Podagogico & Multimodal \\
\hline 08 & Valorat & Descriptivo & Lector experto & Cientifico & Multimodal \\
\hline 09 & Valorat & Descriptivo & Lector experto & Pedagógico & Multimodal \\
\hline 10 & Valorar & Descriptivo & $\begin{array}{l}\text { Lector } \\
\text { semilego }\end{array}$ & Universal & Multimodal \\
\hline 11 & Valorar & Descriptivo & $\begin{array}{l}\text { Lector } \\
\text { semilego }\end{array}$ & Clinico & Multimodal \\
\hline 12 & Valorat & Descriptivo & $\begin{array}{l}\text { Lector } \\
\text { semikgo }\end{array}$ & Clinico & Multimodal \\
\hline 13 & Valorar & Descriptivo & $\begin{array}{l}\text { Lectot } \\
\text { semilego }\end{array}$ & Clinico & Multimodal \\
\hline 14 & Vatorar & Descriptivo & Lector experto & Clinice & Multimodal \\
\hline
\end{tabular}

del modo descriptivo de organización del discurso. Esto significa que la tendencia textual es a nombrar, localizar, calificar, situar, de acuerdo al nivel de concentración del atributo de medición que se esté estimando. Las escalas presentan listas de ítems o reactivos que provocan respuestas que se traducen en descriptores del funcionamiento individual del sujeto evaluado y del grupal (por su condición acumulativa) toda vez que las respuestas son transformadas cuantitativamente para las evaluaciones estadísticas respectivas de cara a las necesidades del investigador o el profesional que emplea estos instrumentos.

En la categoría relación con los participantes se presenta diversidad en la tipologización de la relación entre el productor de la escala y el tipo de lector al que está dirigido. El 64.28\% (9) de las mismas está dirigida a una comunidad discursiva semilego. Esta apreciación se apoya en el hecho de que las escalas están dirigidas a comunidades discursivas que tienen ciertas condiciones de madurez vinculada con el atributo objeto de medida, es decir, la escala está diseñada para un público particular, con características funcionales que le permitan descubrirse reflejados en los reactivos planteados. Esta consideración le da a la escala el carácter de auto-administrado, de allí la presencia de instrucciones donde se le indica al respondiente el conjunto de situaciones que va a enfrentar y las opciones de respuesta con las que cuenta. El 35.72\% (5) restante estuvo dirigida a lectores expertos. Esto se atribuye debido a que las escalas no eran auto administradas, por el contrario, requieren de asistencia profesional para ir provocando las respuestas en el sujeto intervenido y realizando los registros vinculados al caso.

En cuanto a los contextos de circulación de las escalas, se detalla que estas no son exclusivas de un contexto en particular. Como puede notarse el 50\% (7) circulan en el contexto pedagógico, el $7.14 \%$ (1) en el laboral, 7.14\% (1) científico, 14.28 (2) en el clínico. Esta diversidad acentúa el carácter poco restringido que tienen las escalas de actitud ya que se encuentran al servicio de la valoración de atributos vinculados a diversidad de roles que los sistemas humanos desarrollen en los diferentes espacios donde hacen vida. Finalmente se reporta el comportamiento de la categoría modalidad. Aquí el 100\% (14) de las escalas reportó lo multimodal como modo semiótico predominante y esto obedece a la estructuración en tablas que las escalas presentan para viabilizar de mejor modo la acción comunicativa.

De acuerdo con lo señalado podemos concluir que las escalas de actitud se pueden concebir como un género discursivo cuyo macropropósito es valorar la presencia de atributos en sistemas 
humanos mediante un modo de organización discursiva descriptivo que favorece la relación entre un escritor experto y un lector semilego. $\mathrm{Su}$ contexto de circulación es diverso y la modalidad semiótica predominante es la multimodal.

\section{REFERENCIAS BIBLIOGRÁFICAS}

Bajtin, M. (1978). Estética de la creación verbal. México: Siglo XXI.

Bazerman, C. (1999). Changing Regularities of Genre. IEEE Transactions on Professional Communication, 42(1), 1-2.

Beke, R. (2005). El metadiscurso interpersonal en artículos de investigación. Revista Signos, 38(57), 7-18.

Beke, R. (2008). El discurso académico: La atribución del conocimiento en la investigación educativa. Revista Signos, 38(57), 7-18.

Beugrande, R., \& Dressler, W. (1997). Introducción a la lingüística del texto. España: Ariel.

Bhatia, V. (2002). Applied genre analysis: a multi-perspective model. Ibérica, 4, 3-19.

Bolívar, A. (2004). Ponencias y artículos: Dos géneros académicos y un mismo problema. $R e$ vista $A L E D, 4(1), 1-122$.

Bolívar, A. (2008). El informe de arbitraje como género discursivo en la dinámica de la investigación. Revista ALED, 8(1), 1-146.

Calsamiglia, H., \& Tusón, A. (1999). Las cosas del decir: Manual de análisis del discurso. Barcelona: Ariel Lingüística.

Calvi, M. (2010). Géneros discursivos en la lengua del turismo: una propuesta de clasificación. Ibérica, 19, 9-32.

Camacho, H., \& Fontaines, T. (2004). Análisis de tópicos en textos de metodología de la investigación. Revista Encuentro Educacional, 11(2), 229-240.

Charaudeau, P. (2004). La problemática de los géneros: De la situación a la construcción textual. Revista Signos, 37(56), 23-39.

Ciapuscio, G. (1994). Tipos textuales. Buenos Aires: Instituto de Lingüística, Facultad de Filosofía y Letras, Cátedra de Semiología, Ciclo Básico Común, Universidad de Buenos Aires.

Ciapuscio, G. (2003). Formulation and reformulation procedures in verbal interaction between experts and (semi)laymen. Discourse Studies, 5(4), 207-233.

Ciapuscio, G. (2005). La noción de género en la Lingüística Sistémico Funcional y en la Lingüística Textual. Revista Signos, 38(57), 3148.

Ciapuscio, G., Kugel, I., \& Otañi, I. (2005). El conocimiento especializado: el texto de especialidad y los criterios para su tipologización. En M. T. Cabre, Coneixement, llenguatge i discurs especialitzat. España: Institute Universitari de Lingüística Aplicada.

Ezpeleta, P. (2005). La noción de género en la planificación de la docencia de la traducción de la primera lengua extranjera. En I. García Izquierdo (Ed.), El género textual y la traducción: reflexiones teóricas y aplicaciones pedagógicas. Recuperado de http://www.gentt.uji. es/Publicacions/Ezpelet 2005 ArticuloDidactica1.pdf

Fairclough, N. (1995). Critical discourse analysis: The critical study of language. New York: Pearson Education Limited.

Fontaines, T., Camacho, H., \& Finol, M. (2010). Formación de investigadores: Una lectura desde los focos culturales identificados en la historia de la ciencia. Revista multiciencias, 9

\section{Cumbres}


(2), 141-148.

Halliday, M. A. K. (2004). On language and linguistics. En J. Webster (Ed.), Volume 3 in the collected works of M.A.K. Halliday. London-New York: Continuum.

Hernández, R., Fernández, C., \& Baptista, L. (2003). Metodología de la investigación. México: McGraw-Hill.

Herrero, C. (2006). Teoría de pragmática, de lingüística textual y de análisis del discurso. España: Ediciones de la Universidad de Castilla La Mancha.

Kerlinger, F. (1988). Investigación del comportamiento. México: McGraw-Hill.

Loureada, O. (2003). Introducción a la tipología textual. Madrid: Arco

Orlikowski, W., \& Yates, J. (1998). Genre Systems: Structuring Interaction through Communicative Norms. Recuperado de http://ccs.mit.edu/ papers/CCSWP205/

Paltridge, B. (1994). Working with genre: A pragmatic prespective. Journal of Pragmatics, 24(4), 393-406.

Parodi, G. (2008). Géneros discursivos y lengua escrita: Propuesta de una concepción integral desde una perspectiva sociocognitiva. Letras, 51(80), 19-55.

Parodi, G., \& Gramajo, A. (2003). Los tipos textuales del corpus técnico profesional PUCV 2003: una aproximación multiniveles. Revista Signos, 36(54), 207-223.

Parodi, G., Ibáñez, R., \& Venegas, R. (2009). El corpus PUCV-2006 del español: identificación y definición de los géneros discursivos académicos y profesionales. Literatura y lingüística, 20, 75-101.
Simón, J. R. (2006). Propuesta para la determinación de los tipos de textos. Sapiens, 7(1), 148162.

Swales, J. M. (1990). Genre Analysis. Cambridge: Cambridge University Press. 